\title{
Growth of Clostridium difficile and production of toxins $A$ and $B$ in complex and defined media
}

\author{
S. C. HASLAM, J. M. KETLEY, T. J. MITCHELL, J. STEPHEN*, D. W. BURDON† and \\ D. C. A. CANDY
}

Department of Microbiology, University of Birmingham, †The General Hospital, Steelhouse Lane, Birmingham and $\ddagger$ Institute of Child Health, Francis Road, Birmingham

\begin{abstract}
Summary. The ability of several strains of Clostridium difficile to grow and to produce toxins $\mathrm{A}$ and $\mathrm{B}$ in complex and defined culture media has been studied with special reference to the amino-acid composition of the medium. The production of these toxins varied with the strain used and with the composition of the growth medium. Toxin A production was not inextricably linked to production of toxin B since conditions were found in which only one or other toxin was produced.
\end{abstract}

\section{Introduction}

Clostridium difficile is the primary cause of pseudomembranous colitis (Bartlett et al., 1978; George et al., 1978) and one cause of antibiotic-associated diarrhoea (Bartlett et al., 1978). Although the organism is often found in the faeces of healthy neonates, and occasionally, of adults (Keighley, 1981; Viscidi et al., 1981), C. difficile-induced diarrhoea is rare in colonised neonates whereas clinical experience suggests that a significant proportion of colonised adults develop diarrhoea (Lishman et al., 1981). Amongst other factors, the nutritional status of the gut may play an important role in the ability of this pathogen to grow and produce toxins at any particular time.

In this paper we describe experiments in which various strains of $C$. difficile were tested for their ability to grow and to produce toxins $A$ and $B$ in a complex medium and in a range of chemicallydefined media. Particular attention was paid to the effect of withholding specified amino acids. Furthermore, we wished to establish whether there were conditions in which only one of toxins A and B would be produced, because detection of toxin $B$ (and not toxin $\mathrm{A}$ ) is currently used in diagnosis of $C$. difficile infections. Moreover, it has been claimed (Lyerly et al., 1983) that toxins A and B are coproduced in a fixed ratio.

Received 28 May, 1985; accepted 20 Jun., 1985.

* Correspondence should be sent to Dr J. Stephen, Department of Microbiology, P.O. Box 363, University of Birmingham, Birmingham B15 2TT.

\section{Materials and methods}

\section{Strains of $C$. difficile}

The following strains were used: $8051,8089,8410,8864$ and $23289 / 78$ were clinical isolates from The General Hospital, Birmingham; strains B-1 and BT were clinical and environmental isolates, respectively, provided by $\mathrm{Dr}$ S. P. Borriello of The Clinical Research Centre, Harrow, Middlesex. All strains were stored at room temperature in cooked-meat broth.

\section{Culture media}

Complex medium consisted of Bactotryptose (Difco) $20 \% \mathrm{w} / \mathrm{v}$, glucose $0.1 \% \mathrm{w} / \mathrm{v}, \mathrm{Na}_{2} \mathrm{HPO}_{4} 0.2 \% \mathrm{w} / \mathrm{v}, \mathrm{KNO}_{3}$ $0.1 \% \mathrm{w} / \mathrm{v}$ in water (tryptic nitrate broth, TNB). This medium was similar to that described by Redmond et al. (1985) but with two changes: clindamycin was omitted because it appeared to inhibit toxin production in the defined media described below, and the use of the reducing agent sodium formaldehyde sulphoxylate was unnecessary because all cultures were incubated in an anaerobic chamber with an atmosphere of $\mathrm{CO}_{2} 10 \%, \mathrm{H}_{2}$ $10 \%, \mathrm{~N}_{2} 80 \%$. TNB was sterilised by autoclaving ( $15 \mathrm{psi}$, $\left.121^{\circ} \mathrm{C}, 15 \mathrm{~min}\right)$.

Complete defined medium (table I) was based on that described by Rolfe and Finegold (1979) with two modifications. Haemin was omitted because it had no effect on growth or toxin production and the medium was sterilised by membrane filtration (pore size $0.22 \mu \mathrm{m}$ ). Defined amino-acid-deficient media were prepared by omitting the appropriate amino acid from the complete medium.

All media were pre-incubated in the anaerobic chamber for at least 2 days before inoculation.

\section{Growth conditions}

Complete defined medium (in 5-ml volumes) was seeded with several colonies of individual $C$. difficile strains from 2-day-old blood-agar cultures. These broths 
Table I. Composition of complete defined medium

\begin{tabular}{|c|c|c|c|c|c|}
\hline \multicolumn{2}{|c|}{ Amino acids (g) } & \multicolumn{2}{|l|}{ Vitamins $(\mu \mathrm{g})$} & \multicolumn{2}{|c|}{ Minerals (mg) } \\
\hline Histidine & $0 \cdot 1$ & Thiamine & 1000 & $\mathrm{KH}_{2} \mathrm{PO}_{4}$ & 900 \\
\hline Tryptophan & $0 \cdot 1$ & Ca-D-Pantothenate & 1000 & $\mathrm{NaCl}$ & 900 \\
\hline Glycine & $0 \cdot 1$ & Nicotinamide & 1000 & $\mathrm{CaCl}_{2} \cdot 2 \mathrm{H}_{2} \mathrm{O}$ & 26 \\
\hline Tyrosine & $0 \cdot 1$ & Riboflavin & 1000 & $\mathrm{MgCl}_{2} \cdot 6 \mathrm{H}_{2} \mathrm{O}$ & 20 \\
\hline Arginine & 0.2 & Pyridoxine & 1000 & $\mathrm{MnCl}_{2} \cdot 4 \mathrm{H}_{2} \mathrm{O}$ & 10 \\
\hline Phenylalanine & $0 \cdot 2$ & p-Aminobenzoic acid & 50 & $\left(\mathrm{NH}_{4}\right)_{2} \mathrm{SO}_{4}$ & 40 \\
\hline Methionine & 0.2 & Biotin & $12 \cdot 5$ & $\mathrm{FeSO}_{4} \cdot 7 \mathrm{H}_{2} \mathrm{O}$ & 4 \\
\hline Threonine & $0 \cdot 2$ & Folic acid & $12 \cdot 5$ & $\mathrm{CoCl}_{2} \cdot 6 \mathrm{H}_{2} \mathrm{O}$ & 1 \\
\hline Alanine & $0 \cdot 2$ & $\mathrm{~B}_{12}$ & $5 \cdot 0$ & & \\
\hline Lysine & 0.3 & & & & \\
\hline Serine & $0 \cdot 3$ & & & & \\
\hline Valine & $0 \cdot 3$ & & & & \\
\hline Isoleucine & $0 \cdot 3$ & & & & \\
\hline Proline & 0.3 & & & & \\
\hline Aspartic acid & 0.3 & & & & \\
\hline Leucine & 0.4 & & & & \\
\hline Cysteine & 0.5 & & & & \\
\hline Glutamic acid & 0.9 & & & & \\
\hline
\end{tabular}

To the above constituents were added glucose $5.0 \mathrm{~g}$ and sodium carbonate $4.0 \mathrm{~g}$. Water was added to $1 \mathrm{~L}$ and the medium sterilised by membrane filtration.

were incubated at $37^{\circ} \mathrm{C}$ in anaerobic conditions for $24 \mathrm{~h}$. They were diluted 1 in 100 in prereduced saline and $20 \mu 1$ of this diluted suspension was used to inoculate 5-ml volumes of the various test media (TNB, complete defined, and amino acid-deficient) to give final suspensions of $c .10^{3} \mathrm{cfu} / \mathrm{ml}$. (Logistical considerations in setting up this type of experiment inside an anaerobic chamber required maximum simplicity of design and ease of operation. The final dilution of spent medium from starter cultures in amino-acid deficient media was 1 in 2500 . Thus the carry-over of amino acids was minimal, though not necessarily zero.) The broths were incubated at $37^{\circ} \mathrm{C}$ in the anaerobic chamber for 4 days before the culture supernates were collected by centrifugation. Toxin assays were performed on unconcentrated culture supernates.

\section{Toxin assays}

Toxin A was measured quantitatively by the direct sandwich ELISA as described by Redmond et al. (1985). This assay can detect $0.005 \mu \mathrm{g}$ of toxin $\mathrm{A} / \mathrm{ml}$. Toxin A concentrations of $<0.005 \mu \mathrm{g} / \mathrm{ml}$ were recorded as - in tables II and III.

Toxin B titres were determined by a conventional

Table II. Toxin production by $C$. difficile in TNB and complete defined media

\begin{tabular}{|c|c|c|c|c|c|}
\hline \multirow[b]{3}{*}{$\begin{array}{l}\text { C. difficile } \\
\text { strain no. }\end{array}$} & \multicolumn{4}{|c|}{ Toxin production in } & \multirow{3}{*}{$\begin{array}{c}\text { Toxin } \\
\text { production } \\
\text { pattern* }\end{array}$} \\
\hline & \multicolumn{2}{|c|}{ TNB $†$} & \multicolumn{2}{|c|}{ Complete defined medium } & \\
\hline & $\begin{array}{l}\text { Toxin A } \\
(\mu \mathrm{g} / \mathrm{ml})\end{array}$ & $\begin{array}{c}\text { Toxin B } \\
\text { (titre) }\end{array}$ & $\begin{array}{l}\text { Toxin A } \\
(\mu \mathrm{g} / \mathrm{ml})\end{array}$ & $\begin{array}{c}\text { Toxin B } \\
\text { (titre) }\end{array}$ & \\
\hline 8410 & $0 \cdot 14$ & 160 & - & - & I \\
\hline 8864 & - & 6400 & - & 20 & II \\
\hline $\begin{array}{l}8051 \\
23289 / 78\end{array}$ & $\begin{array}{l}0.20 \\
0 \cdot 40\end{array}$ & $\begin{array}{r}160 \\
80\end{array}$ & $\begin{array}{l}0.11 \\
0.70\end{array}$ & $\begin{array}{l}80 \\
80\end{array}$ & III \\
\hline $\begin{array}{l}\text { B-1 } \\
8089\end{array}$ & $\begin{array}{r}3.20 \\
11.00\end{array}$ & $\begin{array}{r}2560 \\
25600\end{array}$ & $\begin{array}{l}0.36 \\
0.28\end{array}$ & $\begin{array}{l}64 \\
80\end{array}$ & IV \\
\hline BT & 3.00 & 2000 & $9 \cdot 60$ & 4000 & V \\
\hline
\end{tabular}

* See Results section.

$\uparrow$ The data recorded for toxin production in TNB are typical of four experiments with each strain. Exceptions are strains 8410 and 8051 which were tested once. 
Table III. Effect of amino-acid deprivation on toxin production

\begin{tabular}{|c|c|c|c|c|c|c|c|c|c|c|}
\hline \multirow[b]{3}{*}{ Medium } & \multicolumn{9}{|c|}{ C. difficile strain } & \multirow[b]{3}{*}{$\begin{array}{l}\text { Amino acid } \\
\text { group* }\end{array}$} \\
\hline & \multicolumn{3}{|c|}{ BT } & \multicolumn{3}{|c|}{ B-I } & \multicolumn{3}{|c|}{$23289 / 78$} & \\
\hline & Growth & $\begin{array}{l}\text { Toxin A } \\
(\mu \mathrm{g} / \mathrm{ml})\end{array}$ & $\begin{array}{c}\text { Toxin B } \\
\text { (titre) }\end{array}$ & Growth & $\begin{array}{l}\text { Toxin A } \\
(\mu \mathrm{g} / \mathrm{ml})\end{array}$ & $\begin{array}{c}\text { Toxin B } \\
\text { (titre) }\end{array}$ & Growth & $\begin{array}{l}\text { Toxin A } \\
(\mu \mathrm{g} / \mathrm{ml})\end{array}$ & $\begin{array}{c}\text { Toxin B } \\
\text { (titre) }\end{array}$ & \\
\hline $\mathrm{TNB}^{\dagger}$ & + & $3 \cdot 0$ & 2000 & + & $3 \cdot 2$ & 2560 & + & 0.40 & 80 & \\
\hline Complete defined $\dagger$ & + & $9 \cdot 6$ & 4000 & + & $0 \cdot 36$ & 64 & + & 0.70 & 80 & \\
\hline $\begin{array}{l}\text { Amino } \\
\text { acid-deficient } \ddagger\end{array}$ & & & & & & & & & & \\
\hline No Pro & - & - & - & - & - & - & - & - & - & \\
\hline Val & - & - & - & - & - & - & - & - & - & \\
\hline Ile & - & - & - & - & - & - & - & - & - & A \\
\hline Leu & - & - & - & - & - & - & - & - & - & \\
\hline Trp & - & - & - & - & - & - & - & - & - & \\
\hline Met & - & - & - & + & 0.09 & 16 & + & 0.06 & 10 & \\
\hline Cys & - & - & - & + & $0 \cdot 13$ & 8 & + & $0 \cdot 19$ & 40 & B \\
\hline Asp & ++ & $5 \cdot 2$ & 1000 & ++ & 0.40 & 64 & ++ & 0.84 & 80 & \\
\hline Thr & ++ & $4 \cdot 5$ & 2000 & ++ & $0 \cdot 31$ & 32 & ++ & 0.78 & 40 & \\
\hline Ser & ++ & 6.9 & 2000 & ++ & $0 \cdot 19$ & 64 & ++ & $0 \cdot 48$ & 40 & $\mathrm{C}$ \\
\hline Phe & ++ & $12 \cdot 0$ & 4000 & ++ & $0 \cdot 33$ & 64 & ++ & $0 \cdot 12$ & 40 & \\
\hline Arg & ++ & $3 \cdot 8$ & 2000 & ++ & $0 \cdot 13$ & 16 & ++ & 0.90 & 40 & \\
\hline His & ++ & 7.0 & 4000 & ++ & 0.06 & 32 & ++ & - & - & D \\
\hline Tyr & ++ & $10 \cdot 8$ & 2000 & ++ & $0 \cdot 33$ & 64 & ++ & - & 10 & \\
\hline Lys & ++ & $5 \cdot 0$ & 2000 & ++ & $0 \cdot 39$ & 128 & ++ & - & 20 & $\mathrm{E}$ \\
\hline Glu & ++ & $3 \cdot 2$ & 1000 & ++ & $0 \cdot 14$ & - & + & 0.50 & 40 & \\
\hline Ala & ++ & $6 \cdot 4$ & 4000 & ++ & 0.16 & - & ++ & 0.80 & 80 & $\mathrm{~F}$ \\
\hline Gly & ++ & $8 \cdot 7$ & 2000 & ++ & 0.09 & - & ++ & 0.80 & 40 & \\
\hline
\end{tabular}

* See Results section

$\dagger$ Data from table II.

$\ddagger$ Amino-acid deficient media were complete defined medium without the named amino acid.

cytotoxicity test with McCoy cells (Redmond et al., 1985). Titrations were performed on doubling dilution series from unconcentrated culture filtrates. Titres were recorded as the dilution that gave a $50 \%$ cell-rounding end-point. A titre of $<8$ was regarded as not significant and recorded as - in tables II and III.

\section{Qualitative estimation of growth}

Cultures were inspected visually after 24 and $96 \mathrm{~h}$. In table III vigorous growth at $24 \mathrm{~h}$ is recorded as ++ , growth at $96 \mathrm{~h}$ as + , and no visible sign of growth at $96 \mathrm{~h}$ as -.

\section{Results}

\section{Medium preparation and toxin production}

Rolfe and Finegold (1979) prepared the defined medium by autoclaving all constitutents except cysteine and sodium carbonate which were filtersterilised and added later. We found that in medium prepared in this way, growth of the organism was unaffected, but production of toxins A and B was extremely variable. On occasions even strain BT, the most prolific toxin producer on filter-sterilised complete defined medium (see table II), did not produce either toxin in autoclaved defined medium.

\section{Toxin production in TNB and complete defined medium}

Toxin production by $C$. difficile grown in TNB and filter-sterilised complete defined medium is summarised in table II. From the strains examined, five different patterns (I-V) of toxin production emerged. Strain 8410 (pattern I) produced small amounts of both toxins in TNB but neither toxin in complete defined medium. Strain 8864 (pattern II) produced high concentration of toxin B in TNB and low concentrations in complete defined media. No toxin A was produced in either medium. Strains 8051 and 23289/78 (pattern III) produced low concentrations of both toxins in both media. Strains B-1 and 8089 (pattern IV) produced high concentrations of both toxins in TNB and lower concentrations of both in complete defined medium. Strain 
BT (pattern V) produced high concentrations of both toxins in each medium.

\section{Amino acid-deficient media}

Three strains, 23289/78, B-1 and BT, i.e., one representative strain from toxin-production patterns from III, IV and V respectively, were chosen for a more detailed study of amino-acid requirements. Strains with patterns I and II were not used because they produced little or no toxins A or B in complete defined medium.

Several experiments were performed with defined amino-acid deficient media prepared by autoclaving and, as with complete defined medium, the results were variable. The results in table III represent an experiment with media prepared from one batch of filtered stock solutions and are internally consistent. Each vertical column showing growth in defined (complete and amino-acid-deficient) media represents cultures which were seeded with the same starter culture. Thus a negative result could not have been due to the non-viability of the inoculum. Each horizontal row represents a medium of constant composition seeded with each of three strains. Thus a negative result could not have been due to accidental variations in the medium because in every case positive results were obtained with some combination. The only exception to this statement was with respect to group A. Omission of any one of these amino acids resulted consistently in no growth and no toxin production. In each case where either toxin A or B was recorded as 'low' or 'negative', the data were checked several times and found to be consistent within the limits of the tests.

Amino acids could be divided into six groups (AF) according to their effect on growth or toxin production. Group-A amino acids were absolute requirements of all three strains for growth. Without growth there was no toxin production. Omission of group-B amino acids (sulphur-containing methionine and cysteine) inhibited growth of strain BT. Strains B-1 and 23289/78 grew poorly and produced low yields of both toxins. Omission of group-C amino acids had little or no effect on growth of, or ability to produce toxins by, any of the three strains. Group D consisted of histidine only, omission of which did not prevent growth of strain $23289 / 78$ but totally inhibited production of both toxins. Omission of group-E amino acids suppressed production of toxin A but not of toxin B by strain 23289/78. Omission of group-F amino acids suppressed production of toxin B but not of toxin A by strain B-1.

\section{Discussion}

The composition of bacteriological media greatly affected the ability of the three strains of $C$. difficile to grow and to produce toxins A and B. Group-A amino acids-proline, valine, leucine, isoleucine and tryptophan were essential for growth in defined medium. Thus the competitive effect of other gut organisms on $C$. difficile could be determined by the availability of these amino acids and the relative efficiencies of amino-acid transport in competing organisms. The absolute requirement for tryptophan may also explain the variability of results observed when complete defined medium was prepared by autoclaving. Tryptophan is acid-labile, especially at high temperature, and may be partially destroyed by autoclaving; other medium constituents may also be heat-labile. This may explain the inability of the strain used by Rolfe and Finegold (1979) to produce toxin (toxin A and toxin B had not then been distinguished) in this medium. Alternatively, their strain could have been similar to strain 8410 which did not produce either toxin in defined medium.

Previously, toxins A and B were thought to be produced at constant ratios irrespective of strain or medium (Lyerly et al., 1983). Within the limits of the accuracy of the two test systems, this may be true for strain BT. However, we have shown here that toxin A can be produced in the absence of detectable toxin B by strain B-1 in glutamate, glycine- and alanine-deficient media, and that toxin $B$ can be produced in the absence of detectable toxin $\mathrm{A}$ by strain 8864 in TNB and by strain $23289 / 78$ on tyrosine- and lysine-deficient media.

The work described in this paper shows that the production of toxins A and B by $C$. difficile depends both on the strain used and on the medium in which it was grown. In particular, it would appear that for some $C$. difficile strains there are amino acids of which there are limiting (at present unspecified) concentrations below which growth of $C$. difficile occurs but toxin production is inhibited. We do not imply that the results presented here constitute a rigid biotyping system; considerably more work needs to be done to develop this approach.

Attempts to predict the pathogenic potential of any strain of $C$. difficile in terms of its ability to produce toxins in vitro would clearly require that the medium reflected closely the nutritional status of the gut at the time of infection. This would be difficult.

We thank the MRC for grant support to $\mathrm{SCH}$ and a studentship to JK. We thank Pfizer Central Research and SERC for a CASE award to TJM. 


\section{REFERENCES}

Bartlett J G, Moon N, Chang T W, Taylor N, Onderdonk A B 1978 Role of Clostridium difficile in antibiotic-associated pseudomembranous colitis. Gastroenterology 75:778-782.

George R H, Symonds J M, Dimock F, Brown J D, Arabi Y, Shinagawa N, Keighley M R B, Alexander-Williams J, Burdon D W 1978 Identification of Clostridium difficile as a cause of pseudomembranous colitis. British Medical Journal 1:695.

Keighley M R B 1981 Antibiotic associated colitis. In: Watts J McK et al. (eds) Infection in surgery; basic and clinical aspects. Churchill-Livingstone, Edinburgh, pp 129-137.

Lishman A H, Al-Jumaili I J, Record C O 1981 Spectrum of antibiotic-associated diarrhoea. Gut 22:34-37.

Lyerly D M, Sullivan N M, Wilkins T O 1983 Enzyme-linked immunosorbent assay for Clostridium difficile toxin $\mathrm{A}$. Journal of Clinical Microbiology 17:72-78.

Redmond S C, Ketley J M, Mitchell T J, Stephen J, Burdon D W, Candy D C A 1985 Detection of Clostridium difficile enterotoxin (toxin A) by ELISA and other techniques. In: Collins $\mathrm{C} \mathrm{H}$, Grange J M (eds) Isolation and identification of microorganisms of medical and veterinary importance. Society of Applied Bacteriology, Technical Series No. 21, Academic Press, London, pp 237-250.

Rolfe R D, Finegold S M 1979 Purification and characterization of Clostridium difficile toxin. Infection and Immunity 25: 191-201.

Viscidi R, Willey S, Bartlett J G 1981 Isolation rates and toxigenic potential of Clostridium difficile isolates from various patient populations. Gastroenterology 81:5-9. 